\title{
MEDICOLEGAL USE OF TROPONIN C EXPRESSION TO IDENTIFY DIFFERENT CAUSES OF CARDIAC DEATHS AT DIFFERENT POSTMORTEM INTERVALS
}

\author{
Enas A. Abdel-Azeem ${ }^{1}$, Nermien A. Ibrahim ${ }^{2}$ and Wafaa F. Hussien ${ }^{2}$ \\ ${ }^{1}$ Medicolegal Authority, Ministry of Justice, Egypt. ${ }^{2,}$ Department of Forensic \\ Medicine \& Clinical Toxicology, Faculty of Medicine, Zagazig University, Egypt.
}

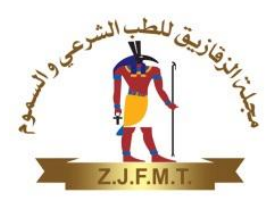

ABSTRACT

Identification of the exact cause and time of death are important questions that have to be answered by the forensic pathologist. Traumatic cardiac injuries is a leading cause of death. This work aimed at using cardiac troponin $\mathrm{C}(\mathrm{cTnC})$ expression to differentiate between different types of cardiac injuries at different postmortem intervals (PMI). This study was performed on 90 forensic autopsies selected in the Medicolegal Department of Ministry of Justice. The cases were divided equally into 5 groups of different causes of death i.e. non-cardiac causes of death (control group), blunt cardiac injury (BCI), civilian cardiac firearm injury, civilian stab injury and sudden cardiac death (SCD). Brown Immunohistochemical expression of TnC was observed in all groups, where the non-cardiac death, blunt injury and firearm injury groups showed less immunohistochemical staining than stab injury and SCD. The density of the cTnC immunohistochemical staining increased by the increase in the PMI. Quantitative morphometric measurement of cTnC immunohistochemical expression was measured. Significant increases in the mean surface area of cTnC immunohistochemical expression were detected in the groups of only stab injury and SCD compared to the other studied groups $(\mathrm{p}<0.001)$, while non-significant differences were detected between non-cardiac, BCI and civilian cardiac firearm injury groups. Besides, the mean surface area of cTnC immunohistochemical expression increased significantly by the increase in the postmortem interval. These findings suggest that the mean surface area of cTnC immunohistochemical expression can differentiate between cardiac and noncardiac deaths, and between the different types of cardiac deaths.

Keywords: Immunohistochemistry; Cardiac Troponin C; Cardiac injuries; Postmortem

\section{INTRODUCTION}

$\mathbf{T}^{\mathrm{s}}$ use of clinical medicine biomarkers is a challenge for the forensic pathologists as their interpretation in a clinical context can be used in postmortem investigation (Beausire et al., 2018). Because cardiac troponin (cTn) has nearly absolute myocardial tissue specificity (Rallou et al., 2013), it is a recommended biomarker for the detection of myocardial necrosis (Thygesen et al., 2012), and has been recommended for the evaluation of the presence and extent of myocardial damage in various causes of death (Zhu et al., 2006).

Antemortem biochemical estimation of cTn level in blood and pericardial fluid, as well as other cardiac muscle proteins, has been previously studied to identify myocardial ischemia as a cause of death (Maeda et al., 2009; Carvajal-Zarrabal et al., 2017 and Palmiere et al., 2018). For cTn $\mathrm{C}$, several works studied its medicolegal use to detect: early myocardial damage (Ortmann et al., 2000), in the comparison between intravital \& postmortem myocardial damage (Ortmann et al., 2001) and the forensic diagnosis of blunt injury (Peter et al., 2006).

The detection of the aforementioned protein markers to investigate myocardial injury in autopsy cases differs from that in clinical findings due to several influencing factors, as for example, the variation in sampling-site results (Chen et al., 2015). Immunohistochemical detection proved to be a better technique to forensic pathology to detect ischemic areas when assessing acute myocardial damage (Ribeiro-Silva et al. 2002). In this regard, the aim of this study is to compare the effect of different cardiac and non-cardiac causes of death on the postmortem cTnC immunohistochemical at different postmortem intervals.

\subsection{Subjects}

\section{SUBJECTS AND METHODS}

This study was conducted on 90 routinely performed forensic autopsies in the Medicolegal Department of Ministry of Justice, Egypt, during the period from February 2012 till March 2014. The bodies were refrigerated where the average interval between death and refrigeration was 4-6 hours. Autopsy procedure was done according 
to Practice Guidelines for Autopsy Pathology (Hutchins, 1994). Cases' age range and sex distribution are presented in table-1. Ethical approval was obtained from the Institution Review Board (IRB) of the Faculty of Medicine, Zagazig University, Egypt.

\subsubsection{Study Design}

Five groups were involved in the study, where each group comprised of 18 cardiac tissue samples. The 5 groups were divided as follows:

- Cardiac trauma was the cause of death of the first 3 groups, where cardiac tissue samples were obtained from 54 autopsy subjects having the following causes of death: blunt cardiac injury, civilian cardiac gunshot injury and civilian cardiac stab injury.

- A group for sudden cardiac death (SCD) cases was the $4^{\text {th }}$ group of cardiac injury i.e. pathology. According to the study of
Rodriguez-Calvo et al. (2008) SCD is a major complication of coronary artery disease which is the most common form of cardiovascular diseases as. According to the mini-symposium about cardiovascular pathology for Milroy (2013) selecting cases with SCD due to coronary artery disease depended on the presence of plaque hemorrhage and acute thrombosis with naked eye examination.

- The remaining 18 autopsy subjects formed the non-cardiac causes of death i.e. other than cardiac injuries/pathology.

Cardiac tissue samples from the anterior wall of the heart (right/left ventricle) were collected at 3 postmortem intervals ( 6 samples/interval): 9-24 hours, 24-48 hours and more than 48 hours. The cause of death was suggested after preforming the routine autopsy and lab procedures.

Table-1: Case Profiles of the Examined Autopsy Cases

\begin{tabular}{|l|c|c|c|}
\hline \multicolumn{1}{c|}{ Groups } & \multirow{2}{*}{$\begin{array}{c}\text { Age Range } \\
\text { in Years }\end{array}$} & \multicolumn{2}{c|}{ Sex } \\
\cline { 3 - 4 } & $20-45$ & 12 & Female \\
\hline Non-cardiac deaths* & $30-60$ & 14 & 6 \\
\hline Blunt injury & $25-65$ & 16 & 4 \\
\hline Gunshot Injury & $30-55$ & 15 & 2 \\
\hline Stab Injury & $45-70$ & 17 & 1 \\
\hline SCD $* *$ & & \\
\hline
\end{tabular}

*Control: cases with various causes of death other than cardiac injuries/pathology

**SCD: sudden cardiac death cases (acute myocardial infarction and coronary atherosclerosis) 
2.1.1 Exclusion Criteria

i. Cases with any cardiac lesion discovered during autopsy other than atherosclerosis.

ii. Cases with severe muscle injury were excluded from the study to avoid interference with cTnC measures.

iii. Cases where deaths with intoxication is involved in the cause of death were excluded.

\subsection{Methods}

\subsubsection{Immunohistochemical Examination:}

Cardiac tissue samples from injured right/left ventricles, obtained from autopsy cases, were fixed in $10 \%$ neutral formal saline. Paraffin sections of 5 um thick were prepared and stained with TnC immunohistochemical stain, using immunoperoxidase staining of formalin fixed paraffin-embedded human heart specimens according to the method described in the study of Kiernan (2000), then examined under light microscopy. Troponin $\mathrm{C}$ expression in cardiac tissue was determined by using mouse anti-Human Troponin $\mathrm{C}$ (Troponin C, Slow Skeletal and Cardiac Muscles, TN-C, TNNC1, TNNC). Immunohistochemical staining for the detection of troponin $\mathrm{C}$ was carried out by means of the avidin-biotin-peroxidase complex method (Dako Company, Wiesentheid/Bavaria, Germany, Biotin Blocking System and Code X0590) according to the manufacturer's instructions.

\subsubsection{Quantitative Morphometric} Measurements:

Surface area of the positive cTnC immunoreactive cardiac tissue was estimated by using "Leica Qwin 500C" (Leica DM L2 c plan 20x1) image analyzer computer system, in the image analyzing unit of Histology and
Cell Biology department, Faculty of dentistry, Cairo University, Egypt. Ten high-power fields (X400) were examined in each of the serial sections in the different studied groups. In each field, the section of the heart was enclosed inside the standard measuring frame; the areas showing brown positive immune reaction for $\mathrm{cTnC}$ were detected then covered automatically by blue binary color mask to calculate the surface area. The reading of each measurement appears in micrometers and, finally, the mean surface area is calculated in all fields examined.

\subsubsection{Statistical Analysis:}

Data were analyzed using SPSS version 19. Analysis of variance (ANOVA) \& least significance difference (LSD) test were used to measure the significant difference among the mean surface areas of cTnC expression in different groups. Data were statistically described in terms of mean and standard deviation (mean $\pm \mathrm{SD}$ ) for surface area $\%$, where differences were considered significant when $\mathrm{p} \leq 0.05$.

\section{RESULTS}

\subsection{Light Microscopic Findings for cTnC Immunohistochemical Staining:}

Under light microscope, immunohistochemical staining of the cardiac tissue samples showed a brown expression of $\mathrm{TnC}$ in all groups, where the non cardiac death (Figure-1), blunt injury (Figure-2) and firearm injury (Figure-3) groups showed less immunohistochemical staining than stab injury (Figure-4) and SCD (Figure-5 for coronary atherosclerosis \& Figure-6 for myocardial infarction) groups. The density of the cTnC immunohistochemical staining increased by the increase in the postmortem interval. 

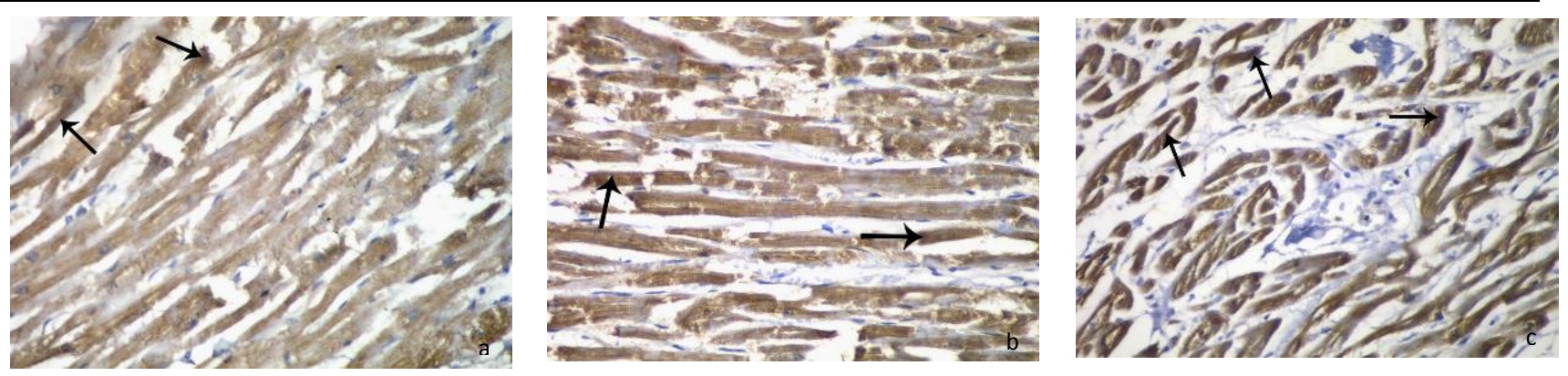

Figure-1: Photomicrographs of myocardium from the non-cardiac death (control) group showing mild positive immunohistochemical brown expression of $\mathrm{Tn} \mathrm{C}$ (thin arrow) that increased with the increase in the PMI, where a: $1^{\text {st }} \mathrm{PMI}, \mathrm{b}: 2^{\text {nd }} \mathrm{PMI}, \mathrm{c}: 3^{\text {rd }} \mathrm{PMI}$.
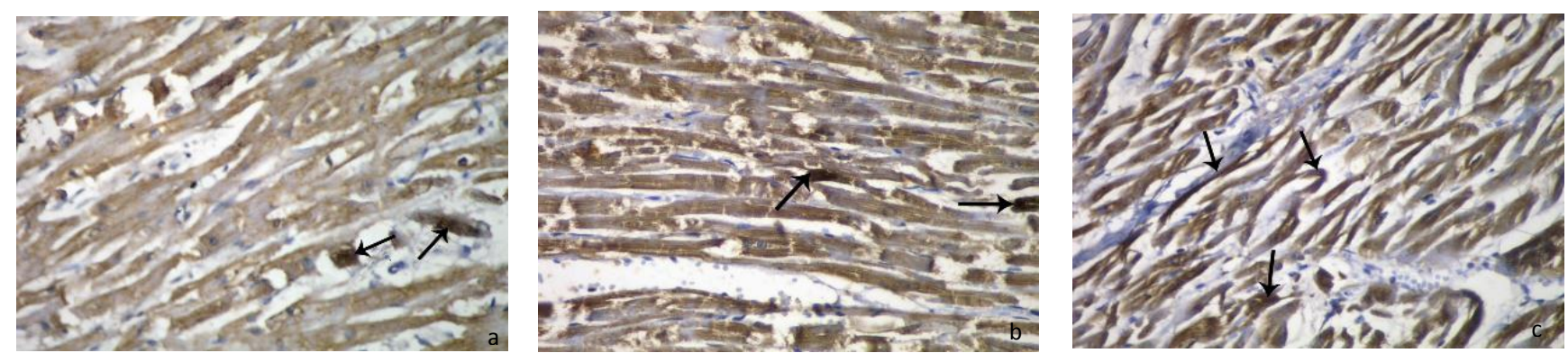

Figure-2: Photomicrographs of myocardium from blunt injury group showing mild positive immunohistochemical brown expression of Tn C (thin arrow) that increased with the increase in the PMI, where a: $1^{\text {st }} P M l, b: 2^{\text {nd }} P M I, c: 3^{\text {rd }} P M I$.
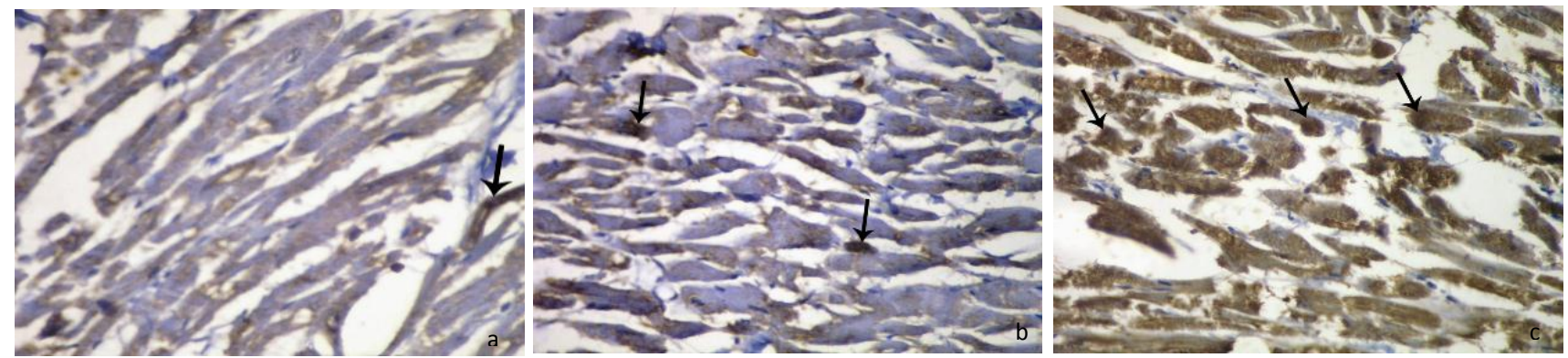

Figure-3: Photomicrographs of myocardium from firearm injury group showing mild positive immunohistochemical brown expression of Tn C (thin arrow) that increased with the increase in the PMI, where a: $1^{\text {st }} \mathrm{PMI}, \mathrm{b}: 2^{\text {nd }} \mathrm{PMI}, \mathrm{c}: 3^{\text {rd }} \mathrm{PMI}$.
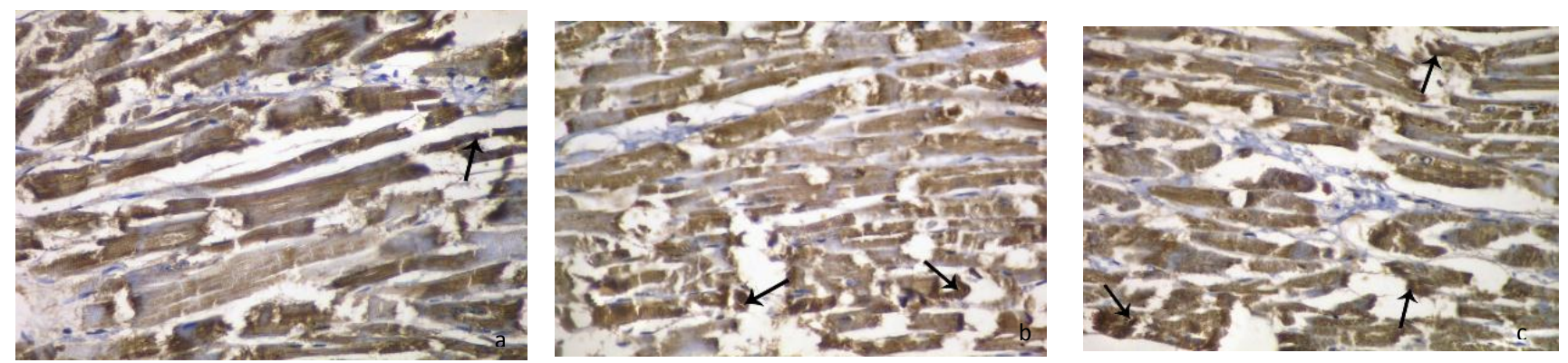

Figure-4: Photomicrographs of myocardium from stab injury group showing moderate to marked positive immunohistochemical brown expression of Tn C (thin arrow) that increased with the increase in the PMI, where a: $1^{\text {st }}$ PMI, b: $2^{\text {nd }}$ PMI, c: $3^{\text {rd }}$ PMI. 

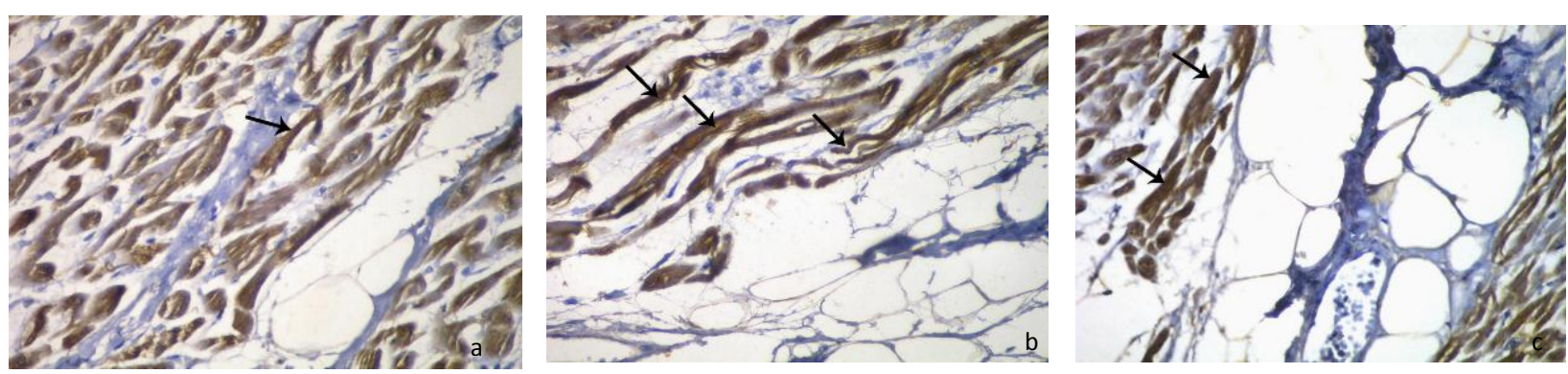

Figure-5: Photomicrographs of myocardium from SCD group (coronary atherosclerosis) showing marked positive immunohistochemical brown expression of $\mathrm{Tn} C$ (thin arrow) that increased with the increase in the PMI, where a: $1^{\text {st }}$ PMI, b: $2^{\text {nd }} \mathrm{PMI}, \mathrm{c:} 3^{\text {rd }} \mathrm{PMI}$.
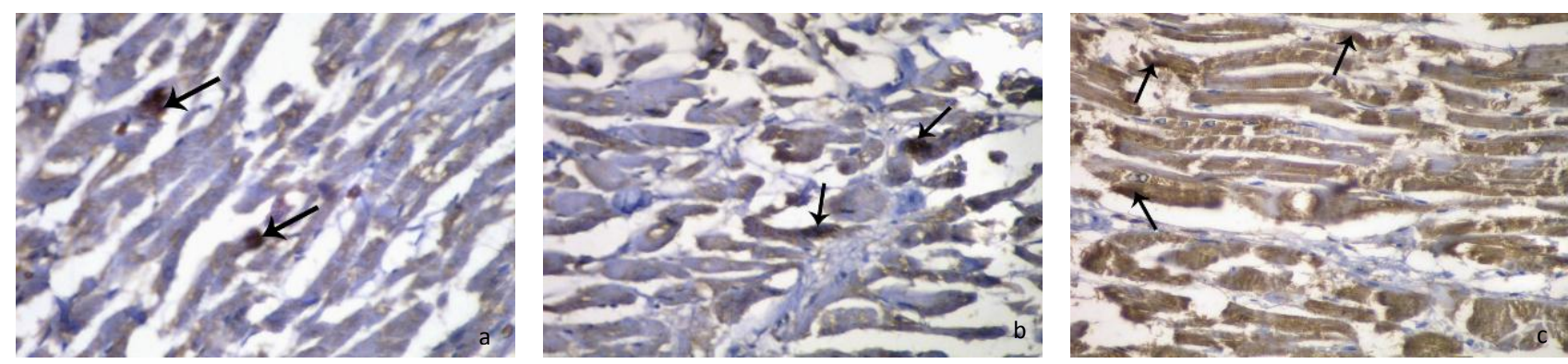

Figure-6: Photomicrographs of myocardium from SCD group (myocardial infarction) showing marked positive immunohistochemical brown expression of Tn C (thin arrow) that increased with the increase in the PMI, where a: $1^{\text {st }} \mathrm{PMI}, \mathrm{b}: 2^{\text {nd }} \mathrm{PMI}, \mathrm{c}: 3^{\text {rd }}$ PMI.

\subsection{Quantitative Morphometric Analysis for Immunohistochemical cTnC} Expression:

The group of cardiovascular diseases showed the highest significant increases of in the mean surface area of cTnC expression compared to the other groups, followed by the stab injury group (Table-2). Nonsignificant differences were recorded in the mean surface area of cTnC expression of blunt injury and gunshot injuries groups when compared to the non-cardiac group and when compared to one another (Table$2)$. By the increase in the postmortem interval, the mean surface area of cTnC expression showed significant increases in all groups, where the recorded levels after 48 hours postmortem showed significant increases compared to the levels recorded during the others two intervals followed by the 24-48 hours interval (Figure-7, Table-3).
Figure-7: Changes in the Mean Surface Area of Cardiac TnC Expression in the Studied Groups during Different Postmortem Intervals

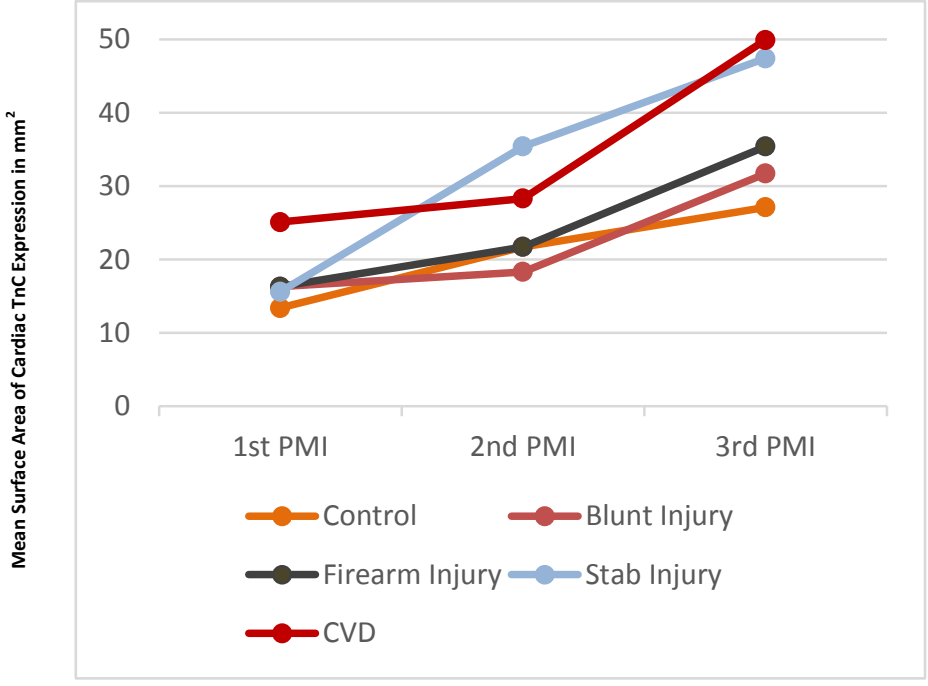


Table-2: Comparison of the Mean Surface Area of Cardiac Troponin C Expression among Different Groups

\begin{tabular}{|c|c|c|c|c|c|c|}
\hline \multicolumn{2}{|c|}{ Groups } & $\begin{array}{c}\text { Non- } \\
\text { Cardiac }\end{array}$ & Blunt injury & $\begin{array}{c}\text { Gunshot } \\
\text { Injury }\end{array}$ & $\begin{array}{c}\text { Stab } \\
\text { Injury }\end{array}$ & SCD \\
\hline \multirow{2}{*}{$\approx$} & $\mathbf{1}^{\text {st }}$ PMI & $13.4 \pm 7$ & $16.3 \pm 1.1$ & $16.3 \pm 2.3$ & $15.6 \pm 2.3$ & $25.1 \pm 1.9^{\text {abcd }}$ \\
\cline { 2 - 7 } & $2^{\text {nd }}$ PMI & $21.7 \pm 11$ & $18.3 \pm 1.2$ & $21.7 \pm 2.2$ & $35.4 \pm 4.1^{\mathrm{bce}}$ & $28.3 \pm 1.3^{\mathrm{bc}}$ \\
\cline { 2 - 7 } & $\mathbf{3}^{\text {rd }}$ PMI & $27.1 \pm 18$ & $31.7 \pm 5.6$ & $35.4 \pm 3.7$ & $47.4 \pm 6.3^{\mathrm{bc}}$ & $49.9 \pm 2.1^{\mathrm{bc}}$ \\
\hline
\end{tabular}

Data are expressed in terms of mean \pm standard deviation $\mathrm{mm}^{2}$, PMI: postmortem interval, SCD: sudden cardiac death, Significance is considered when at $<0.0 .5,1^{\text {st }}$ PMI: 9-24 hours after death, $2^{\text {nd }}$ PMI: $24-48$ hours after death, $3^{\text {rd }}$ PMI: $>48$ hours after death, a: significant increase when compared to the non-cardiac deaths group, b: significant increase when compared to the blunt injury group, c: significant increase when compared to the gunshot injuries group, d: significant increase when compared to the stab injury group, e: significant increase when compared to the SCD group

Table-3: Comparison of the Mean Surface Area of Cardiac Troponin C Expression among Different Postmortem Intervals

\begin{tabular}{|l|c|c|c|}
\hline \multirow{2}{*}{ Groups } & \multicolumn{3}{c|}{ Postmortem Intervals } \\
\cline { 2 - 4 } & $\mathbf{1}^{\text {st }}$ PMI & $\mathbf{2}^{\text {nd }}$ PMI & $\mathbf{3}^{\text {rd }}$ PMI \\
\hline Non-cardiac Deaths & $13.4 \pm 7$ & $21.7 \pm 11$ & $27.1 \pm 18$ \\
\hline Blunt injury & $16.3 \pm 1.1$ & $18.3 \pm 1.2^{\mathrm{A}}$ & $31.7 \pm 5.6^{\mathrm{AB}}$ \\
\hline Gunshot Injury & $16.3 \pm 2.3$ & $21.7 \pm 2.2^{\mathrm{A}}$ & $35.4 \pm 3.7^{\mathrm{AB}}$ \\
\hline Stab Injury & $15.6 \pm 2.3$ & $35.4 \pm 4.1^{\mathrm{A}}$ & $47.4 \pm 6.3^{\mathrm{AB}}$ \\
\hline SCD & $25.1 \pm 1.9$ & $28.3 \pm 1.3^{\mathrm{A}}$ & $49.9 \pm 2.1^{\mathrm{AB}}$ \\
\hline
\end{tabular}

Data are expressed in terms of mean \pm standard deviation $\mathrm{mm}^{2}$, PMI: postmortem interval, SCD: sudden cardiac death, Significance is considered when at $<0.0 .5,1^{\text {st }}$ PMI: 9-24 hours after death, $2^{\text {nd }}$ PMI: $24-48$ hours after death, $3^{\text {rd }}$ PMI: $>48$ hours after death, A: significant increase when compared to $1^{\text {st }}$ PMI, B: significant increase when compared to the $2^{\text {nd }} P M I$

\section{DISCUSSION}

Cardiac injuries has a wide spectrum, especially, due to trauma that has a high mortality rate (Leite et al., 2017). Moreover, it has been stated that cardiac troponins (cTns) are more sensitive and specific marker of cardiomyocyte injury than other biomarkers (Roffi et al., 2016). In the current study, cardiac troponin C (cTnC) showed a specific expression pattern regarding cardiac traumatic groups i.e. blunt, gunshot and stab injuries, where cardiac stab injury caused a significant increase in the mean surface area of cTnC expression compared to the blunt and gunshot injuries.
On the exposure to a traumatic event, a provocation of the 'defense reaction' occurs due to sympathetic efferent activity with subsequent tachycardia and an increase in blood pressure i.e. the response that prepares the organism for 'fight or flight' (Kirkman and Little, 1994). As calcium channels in the heart are under the effect of sympathetic ( $\beta$ receptors) and parasympathetic (muscarinicreceptors) modulation (Reuter, 1983), the aforementioned sympathetic activity will lead to an increase in $\mathrm{Ca}^{2+}$ influx, contributing to the increase in myocardial contractility (Noble, 1984). Troponin $C$ is the calciumbinding protein in the troponin complex in cardiomyocytes, where a rise in the intracellular $\mathrm{Ca}^{2+}$, with subsequent increased cTnC binding, is the event that initiates contraction in cardiac muscle $(\mathbf{L i}$ and Hwang, 2015). Hence it can be concluded that traumatic events can cause an increase in the cTnC expression through sympathetic stimulation and a subsequent increase in the in $\mathrm{Ca}^{2+}$ influx into cardiomyocytes. This conclusion is supported by the study of 
Gennaro et al. (2008) who reported an elevation in cardiac troponins by mechanical injury through direct trauma to the heart.

According to the previous conclusion, the increased cTnC expression in the stab injury group of the current study compared to the other cardiac trauma groups can be attributed to the duration of posttraumatic sympathetic stimulation during the survival period prior to death, in which cTnC expression in the blunt and firearm cardiac injury groups didn't show any significant differences compared to the non-cardiac group, while stab injury group showed a significant cTnC expression increase. For more explanation, injury biomechanics of the 3 cardiac traumatic groups have to be referred to.

Blunt cardiac injury (BCI) can be fatal when it results from direct high-impact to the anterior chest wall (Fulda et al., 1991), which leads to instant death either from ventricular fibrillation or cardiac rupture (Stein et al., 1982) due to ventricular injury at end-diastole when the ventricles are at maximal distention (Getz et al., 1986). For civilian gunshot, although it is considered a relatively lowenergy injury, severe damage might be induced (Burg et al., 2009) due to the transmitted kinetic energy with the development of two zones of tissue damage: the permanent track produced by the bullet passage, and a surrounding area of contused tissue produced by the temporary cavitation (Stefanopoulos et al., 2014). These wounds are associated with more rapid and less selflimited bleeding, and pericardial tamponade or hemorrhagic shock frequently develops rapidly with rapid death (Symbas, 1976).

In civilian stabbing, according to Saukko and Knight (2004) ${ }^{\text {a }}$, tissue injury is caused by forward thrust of any sharp instrument (as knives) towards the chest and penetrates the heart, or, rarely, due to inward displacement of ribs or sternal fragments, where the stabbed victim is often moving and dynamic. Symbas (1976) stated that stab wounds are similar to surgical incisions and usually cause little cellular destruction adjacent to the wound. Such wounds in the relatively thick-walled right or left ventricles may spontaneously seal after various amounts of initial bleeding. Also, Perdekamp et al. (2000) has reported a prolonged course in penetrating stab injury to the heart, due to the potential contraction of cardiac muscle and blood clot formation which are associated with a ventricular rather than an atrial injury due to wall thickness.

In SCD group of the current study, a significant increase in the mean surface area of cTnC expression was detected compared to the non-cardiac death group (control group). It has to be noted that atherosclerotic heart disease can lead to acute myocardial infarction (and sudden death) when critical narrowing $(75 \%)$ of one or more coronary arteries is present (Kotabagi et al., 2000), and this, in turn, causes the release of troponin protein complex which is a sensitive and specific marker of cardiomyocyte injury than other biomarkers (Roffi et al., 2016).

The significant increase in the mean surface area of cTnC expression by the increase in the postmortem period, as recorded in the current study, can be attributed to the study of Majno and Joris (1995) who explained the postmortem changes in enzyme activity and cell ultrastructure by what is known as postmortem autolysis, where after death anoxic effects (ischemia, glycolysis, and proteolysis) lead to intracellular acidification and changes in ionic composition with damage to the lysosomal membranes and leakage of their enzymes into the cytoplasm, consequently, widespread leakage of cellular enzymes and macromolecules into the extracellular space occurs. Also, Nick et al. (2010) found that postmortem cardiac markers levels like cardiac troponins (and creatine kinase) may be elevated in many deaths because of the nonspecific myocardial damage due to hypoxia during the agonal period. The time related decline in myocytes viability is presented in the study of Hessel et al. (2008) who stated that sharp decline in cell viability was observed between 12 and $18 \mathrm{~h}$, while extensive cell death was demonstrated at 24 and $30 \mathrm{~h}$.

According to the results of the current study, it can be concluded that postmortem measuring of cTnC immunohistochemical expression can be used to differentiate 
between death from cardiac stabbing and death from other causes of cardiac trauma, on one side, and other non-cardiac causes of death on the other side. Sudden cardiac death due to myocardial infarction can produce similar effect as cardiac stabbing on cTnC immunohistochemical expression. Further work is to be recommended to study the relation between $\mathrm{cTnC}$ release in relation to posttraumatic survival period and sympathetic stimulation.

\section{Conflict of Interest}

There is no conflict of interest.

\section{REFERENCES}

Beausire T, Faouzi M, Palmiere C, Fracasso T, Michaud K. High-sensitive cardiac troponin hs-TnT levels in sudden deaths related to atherosclerotic coronary artery disease. Forensic Sci Int. 2018; 289; 238-243.

Burg A, Nachum G, Sala, M, Haviv B, Heller S, Velkes S, Dudkiewicz I. Treating civilian gunshot wounds to the extremities in a level 1 trauma center: Our experience and recommendations. Isr Med Assoc J. 2009; 11:546-551.

Carvajal-Zarrabal O, Hayward-Jones PM, Nolasco-Hipolito C, Barradas-Dermitz DM, Calderón-Garcidueñas AL, López-Amador N. Use of Cardiac Injury Markers in the Postmortem Diagnosis of Sudden Cardiac Death. J Forensic Sci. 2017; 62:1332-1335.

Chen JH, Inamori-Kawamoto O, Michiue T, Ikeda $\mathrm{S}$, Ishikawa $\mathrm{T}$, Maeda $\mathrm{H}$. Cardiac biomarkers in blood, and pericardial and cerebrospinal fluids of forensic autopsy cases: A reassessment with special regard to postmortem interval. Leg Med. 2015; 17-5; 343-350.

Fulda G, Brathwaite CEM, Rodriguez A, Turney SZ, Dunham CM, Cowley RA. Blunt traumatic rupture of the heart and pericardium: a ten year experience (1979-1989). J Trauma. 1991; $31: 167-73$.

Gennaro EL, Brunetti ND, Cuculo A, Pellegrino PL, Izzo P, Roma F, Di-Biase M. Increased Troponin Levels in Nonischemic Cardiac Conditions and Noncardiac Diseases. J Interv Cardiol. 2008; 21:129-139.

Getz BS, Davies E, Steinberg SM, Beaver BL, Koenig FA. Blunt cardiac trauma resulting in right atrial rupture. JAMA. 1986; 255:761763.

Hessel M, Michielsen E, Atsma D, Schalij M, van der Valk E, Bax W, W.T.Hermens WT, van Dieijen-Visser MP, van der Laarsea A. Release kinetics of intact and degraded troponin I and $\mathrm{T}$ after irreversible cell damage. Exp Mol Pathol. 2008; 85:90-95.

Hutchins GM. Practice guidelines for autopsy pathology. Autopsy performance. Autopsy Committee of the College of American Pathologists. Arch Pathol Lab Med. 1994; 118(1):19-25.

Kiernan JA. Histological and Histochemical Methods. Theory and Practice, 3rd Edition, Butterworth Heinemann, Oxford, Boston. 2000.

Kirkman E, Little R. Central control of cardiovascular responses to injury. In: Rothwell N, Berkenbosch F (Eds) Brain Control of Responses to Trauma. Cambridge, Cambridge University Press, 1994; 202-38.

Kotabagi RB, Apte VV, Pathak PR. Postmortem diagnosis of early myocardial infarction $\mathrm{Med} J$ Armed Forces India. 2000; 56(2):99-102.

Leite L, Gonçalves L, Vieira DN. Cardiac injuries caused by trauma: Review and case reports. $J$ Forensic Leg Med. 2017; 52:30-34.

Li MX, Hwang PM. Structure and function of cardiac troponin C (TNNC1): Implications for heart failure, cardiomyopathies, and troponin modulating drugs. Gene. 2015; 571(2):153166.

Maeda H, Michiue T, Zhu BL, Ishikawa T, Quan L. Analysis of cardiac troponins and creatine kinase $\mathrm{MB}$ in cerebrospinal fluid in medicolegal autopsy cases. Leg Med. 2009; 1:S266-S268.

Majno G., Joris I. Apoptosis, oncosis, and necrosis: An overview of cell death. Am $J$ Pathol. 1995; 146(1):3-13.

Milroy CM. Coronary artery disease, sudden death and implications for forensic pathology practice. Diag Histopath. 2013; 19(1):479-485.

Nick I, Bradley J, Christine N, Kim A. The Role of Postmortem Cardiac Markers in the Diagnosis of Acute Myocardial Infarction. $J$ Forensic Sci. 2010; 55(4): 1088-1091.

Noble D. The surprising heart, a review of recent progress in cardiac electrophysiology. $J$ Physiol. 1984; 353:1-50.

Ortmann C, Pfeiffer H, Brinkmann B. A comparative study on the immunohistochemical detection of early myocardial damage. Int J Leg Med. 2000; 113:215- 220.

Ortmann C, Pfeiffer H, Brinkmann B. Immunohistochemical alterations after intravital and post-mortem traumatic myocardial damage. Int J Leg Med. 2001; 115; 1437-1596. 
Palmiere C, Tettamanti C, Bonsignore A, De Stefano F, Vanhaebost J, Rousseau G, Pia Scarpelli M, Bardy D. Cardiac troponins and NT-proBNP in the forensic setting: Overview of sampling site, postmortem interval, cardiopulmonary resuscitation, and review of the literature. Forensic Sci Int. 2018; 282:211218.

Perdekamp MG, Riede UN, Pollak S. Penetrating stab injury to the heart with unusually long survival. Arch Kriminol. 2000; 206(3-4):102109.

Peter J, Kirchner A, Kuhlisch E, Menschikowski M, Neef B, Dreßler J. The relevance of the detection of troponins to the forensic diagnosis of cardiac contusion. Forensic Sci Int. 2006; 2-3; 127-133.

Rallou S, Dimitris G, Sotiris A, Stavroula P, Chara S. Diagnostic Value of Cardiac Troponin I in Postmortem Diagnosis of Myocardial Infarction. Am J Forensic Med Path. 2013; 34: 139-141.

Reuter H. Ion channels in cardiac cell membranes. Annu Rev Physiol. 1984; 46:473-484.

Ribeiro-Silva A, Martin CC, Rossi MA. Is immunohistochemistry a useful tool in the postmortem recognition of myocardial hypoxia in human tissue with no morphological evidence of necrosis? Am J Forensic Med Pathol. 2002; 23:72-77.

Rodríguez-Calvo MS, Brion M, Allegue C, Concheiro L, Carracedo A. Molecular genetics of sudden cardiac death. Forensic Sci Int. 2008; 182(1-3):1-12.

Roffi M, Patrono C, Collet JP, Mueller C, Valgimigli M, Andreotti F, Bax JJ, Borger MA, Brotons C, Chew DP, Gencer B, Hasenfuss G, Kjeldsen K, Lancellotti P,
Landmesser U, Mehilli J, Mukherjee D, Storey RF, Windecker S. ESC Scientific Document Group; 2015 ESC Guidelines for the management of acute coronary syndromes in patients presenting without persistent STsegment elevation: Task Force for the Management of Acute Coronary Syndromes in Patients Presenting without Persistent STSegment Elevation of the European Society of Cardiology (ESC). Eur Heart J. 2016; 37(3):267-315.

Saukko P, Knight B. The pathology of wounds. Knight's Forensic Pathology. $3^{\text {rd }}$ Ed. London: Edward Arnold Ltd., CRC Press; 2004 136173.

Stefanopoulos PK, Filippakis K, Soupiou OT, Pazarakiotis VC. Wound ballistics of firearmrelated injuries-Part 1: Missile characteristics and mechanisms of soft tissue wounding. Int $J$ Oral Maxillofac Surg. 2014; 43(12):14451458.

Stein PD, Sabbah IN, Viano DC, Vostal JJ. Response of the heart to non-penetrating cardiac trauma. J Trauma. 1982; 22:364-73.

Symbas PN. Cardiac trauma. Am Heart J. 1976; 2(3):387-396.

Thygesen K, Alpert JS, Jaffe AS, Simoons ML, Chaitman BR, White HD. Third universal definition of myocardial infarction. Eur Heart J. 2012; 33:2551-2567.

Zhu BL, Ishikawa T, Michiue T, Li DR, Zhao D, Oritani S, Kamikodai Y, Tsuda K, Okazaki S, Maeda H. Postmortem cardiac troponin $\mathrm{T}$ levels in the blood and pericardial fluid. Part 1: analysis with special regard to traumatic causes of death. Leg Med .2006; 8:86-93. 